\title{
Experimental Moulded Soles and Shoe Lasts
}

\author{
JOHN GIRLING* \\ Manager, Orthopaedic Appliance and Artificial Limb Workshop, Christian Medical College and Hospital, \\ Vellore, South India \\ M. A. HAMEED, L.L.G.M. \\ Leather Technician, Orthopaedic Appliance and Artificial Limb Workshop, Christian Medical College and \\ Hospital, Vellore, South India
}

\author{
A. J. SELVAPANDIAN, B.sc., м.в., M.s. \\ Professor, Department of Orthopaedic Surgery, \\ Christian Medical College and Hospital, Vellore, South India
}

For a period of 6 years rigid soled shoes have been recommended for the prevention of reulceration of the deformed and anaesthetic feet of leprosy patients (Price i 960 and Ward i 962). The dramatic reduction of plantar pressures given by a flat rigid soled shoe was demonstrated by Baumann et al (1963). At the Christian Medical College Hospital, Vellore, S. India, and the Schieffelin Leprosy Research Institute, there are many cases of deformed feet that have been kept free of ulcers by the use of these shoes. But it has long been a worry that these shoes cause instability at the tarsal, especially on rough ground. A study of tarsal disintegration (Harris, Brand) has given rise to the thought that this instability may be a factor related with later tarsal disintegration, especially when the shoes have been used immediately after plaster of Paris immobilization. Apart from the instability caused by the rigid soled shoe the weight and the bulk of the shoe makes it unpopular with the patients.

With these factors in mind it was decided to try and develop a new design of shoe that would prevent reulceration but not have the disadvantages of the rigid soled shoe. To decrease the instability the foot should be as near the ground as possible and this would also help eliminate the bulk of the shoe. It was felt that an accurately moulded insole would help distribute the walking plantar pressures as well as give support to the tarsal area of the foot. The mould would have to be in the shape of the walking foot and not of the foot when the patient was standing or sitting. For this reason the standard orthopaedic method of making a moulded sole would not be suitable. Various materials were experimented with to find one that would be inexpensive, easy to handle and would give the correct moulding. Brand found a method of using rubber latex and cork dust which was suitable for our needs. A system of construction has been developed and this is now being used to make footwear for a selected number of deformed feet. This paper explains and gives details of the method used. The shoes described are meant to be used for the deformed, badly scarred or shortened feet that can not be kept free of ulcers in the standard microcellular rubber sandal (Price I960 and Ward I 962). At this stage it is too early to say that this is the answer to our problem and the footwear is still in the experimental stages even though the results have so far been encouraging. A method is also described for making accurate shoe lasts for deformed feet. Again the number that have so far been made is small, but with this method it is possible to obtain an accurately fitting upper, an important factor when the foot must be held firmly in place on a moulded sole.

For the foot that is not badly deformed but has an uneven or badly scarred plantar surface moulding is going to help distribute the weight more evenly over the plantar aspect. For these cases measurements needed for an orthopaedic shoe are taken (British Standard I96I). The shoes are made on a standard last that has been adapted to suit the measurements and minor deformities of the foot. The bottom of the last is built up with layers of leather, corksheeting or

* Sponsored by the Swiss Emmaus Association. Experimental Moulded Soles 103 
cardboard to a depth of $15 \mathrm{~mm}$ to allow room for the insole. The shoe is then made on the last in the usual way.

At the fitting of the shoe a mixture of coarse cork dust and rubber latex is made up in volume; six of cork to one of latex. Raw rubber latex can be used but it is better to use pre-vulcanized latex when possible, as it makes a stronger mould. When an open design of sandal is being used, strips of X-ray film are placed down the insides of the upper to prevent the cork from being squeezed out of the gaps. The cork and latex is spread in the shoe to a depth of about $20 \mathrm{~mm}$, and left loose and not pressed down. A slightly greater amount is put in the area of the medial arch or other non-weightbearing areas of the foot depending on the deformity. The microcellular rubber insole I5 to 20 Shore; $7 \mathrm{~mm}$ thick is put in over the top of the cork (Fig. I). It will be found necessary to press the

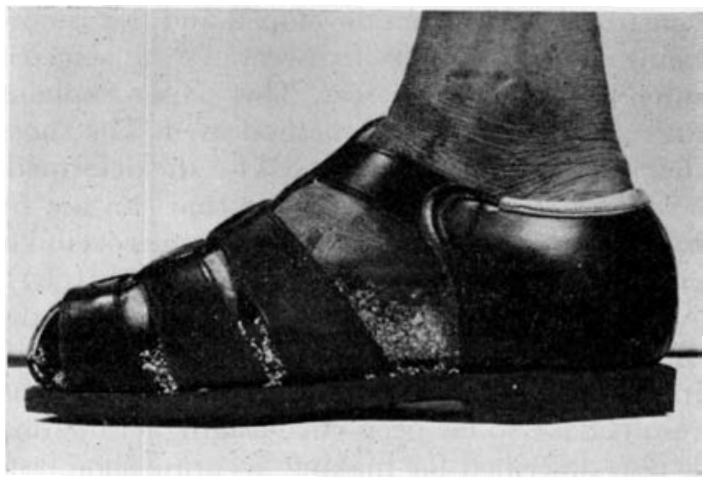

FIG. I

The foot in the sandal ready for forming the mould. It will be noticed that at the foot especially the heel is too far out of the sandal. After 15 minutes of walking the foot will have settled down correctly inside the sandal. The $\mathrm{X}$-ray film across the medial arch is preventing the cork from being squeezed out. The black microcellular rubber can just be seen between the cork and the foot.

rubber down a little to allow room for the foot to slide into the shoe. A design of upper that opens right down to the toes eliminates the danger that the sole will be incorrectly pressed at this stage forming wrong moulding. The patient is asked to stand and then walk about for five minutes. The moulding is checked to see that it is high enough up into the arch. This is done without removing the shoe, an open design of sandal makes this job easy; with a closed shoe it is nearly impossible and the checking has to be done at the finishing. The patient should wear the shoes for at least half an hour, half of this time should be spent in gentle walking on an even surface. The shoe is then removed and any cork that has come up over the sides of the microcellular rubber is removed. In a sandal where the cork can be seen in the gaps, the $\mathrm{X}$-ray film is removed and the cork is painted with the sole dye or a strip of leather is stuck onto it. It will be found that the cork presses up under the toes and onto the front of the toes. In sandals this cork can be removed at the finishing stage. When a closed shoe is being used a wad of cotton-wool should be placed in the toes of the shoes before the cork is put in. This piece of wool can then be removed at the finishing stage (Brand).

\section{Shoe Lasts for badly deformed and shortened feet}

It is vcry difficult and time consuming to carve correctly shaped wooden lasts for deformed feet, to get over this difficulty we make the lasts from a negative plaster cast, out of polyester resin and cork dust.

Plaster cast, materials needed:

Shcet of $20 \mathrm{~mm}$ thick 15 Shore microcellular rubber $20 \times 30 \mathrm{~cm}$.

Pieces of $3 \mathrm{~mm}$ thick sponge rubber

Rubber or plastic tube $8 \mathrm{~mm}$ diameter, length $30 \mathrm{~cm}$.

Plaster scissors

Indelible pencil

Two 4 inch quick setting plaster bandages

Vaseline.

\section{Method}

The patient is asked to stand with the deformed foot on the microcellular rubber sheet. Pieces of sponge rubber are then placed under the toes to give as much toe spring as is possible but without creating too much pressure on the toes (Fig. II). With a shortened foot this is very nearly impossible and the foot has to be left flat. It is not the aim at this stage to create a great deal of moulding to the sole as the moulding will be formed at the finish with the cork and latex insole. The patient sits while the foot is vaselined.

\section{IO4 Leprosy Review}




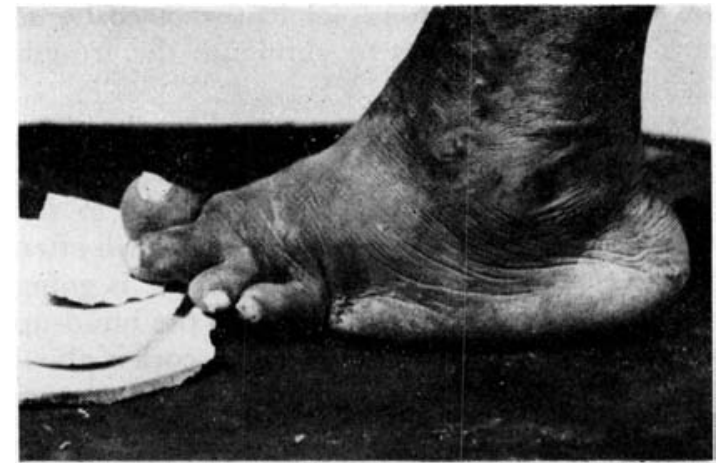

FIG. II

The foot on the microcellular rubber with the sponge rubber forming the toe spring in position.

The rubber tube is placed along the dorsum of the foot and is held in place by an assistant or by the patient himself. The foot is wrapped completely in plaster bandage to just above the maleoli, care being taken that there is adequate thickness around the heel. The foot is placed again on to the microcellular rubber sheet with the sponge rubber forming the toe spring in the correct position. The patient is asked to stand and to take equal weight on both feet. The plaster is moulded with the hands around the heel, ankle and the dorsum of the foot. With the indelible pencil lines are drawn across the bump

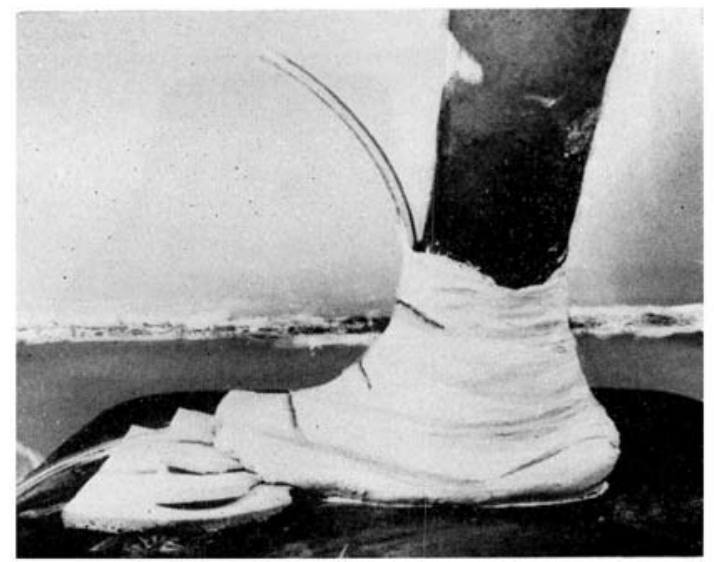

FIG. III

The plastered foot with the rubber tube in place. The patient is standing while the plaster dries.

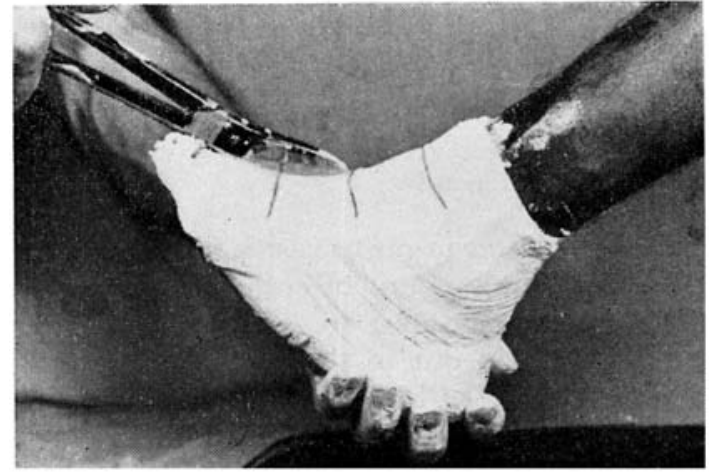

FIG. IV

With the rubber tube removed, cutting up the dorsum of the plaster.

formed by the tube (Fig. III). Just before the plaster starts to become warm the patient is asked to sit. The tube is pulled out and the plaster scissors are introduced into the gap left by the tube. The plaster is then cut right up the dorsum from the toes (Fig. IV) and removed from the foot by sliding it backwards and downwards; care being taken that the heel is not pushed out of shape, especially in the cases where the patient has a posterior protruding heel (Fig. V). The plaster cast is then closed up again aligning the pencil marks. Another plaster bandage is wrapped round it. The patient's name is written on the outside and it is left to dry.

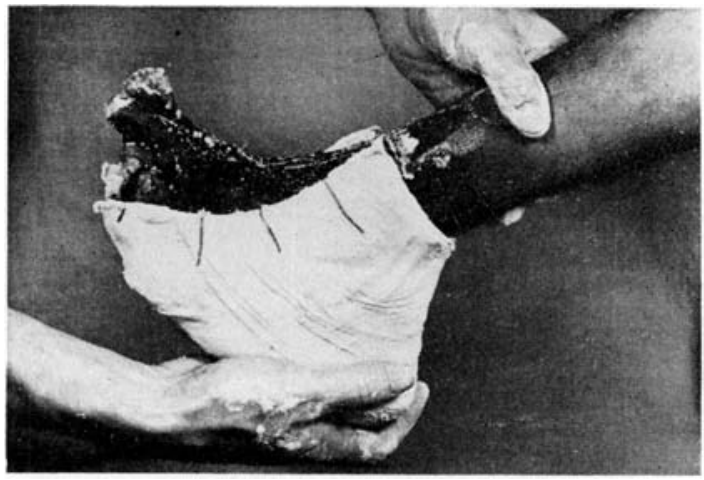

FIG. V

Sliding the plaster cast backwards off the patient's foot. 


\section{Making the Last}

The last is made from polyester resin and cork dust, a method suggested by Mr John Gleave of Hong Kong.

\section{Method}

The dried plaster negative cast is filled with dry cork dust. The amount of cork dust needed is then weighed and put to one side. Polyester resin is weighed out to the quantity of $100 \%$ resin to $40 \%$ cork. The polyester resin is mixed in the usual way (Polyester Hand Book 1963) and then the cork is mixed well into it. The cork and polyester is put into the negative cast, a little at a time and is pushed well down using a spatula, care being taken that the toes are adequately filled. The cast is left to set for 24 hours. The plaster is then removed. If it is found that the surface of the last is at all crumbly then a further mixture of polyester can be painted onto it. A greater percentage of polyester can be used in the initial mixture, but this is apt to make the last too hard for the shoemaker when hammering in nails.

\section{Last Adaptation}

If a closed toe design of boot is going to be made the front of the last will have to be built out to a depth of $25 \mathrm{~mm}$. with leather. The leather is tacked on while it is wet so that it can be formed to the correct shape; it should be in the shape of a toe cap and allow clearance inside the boot for the toes. If an open toe boot is to be used then

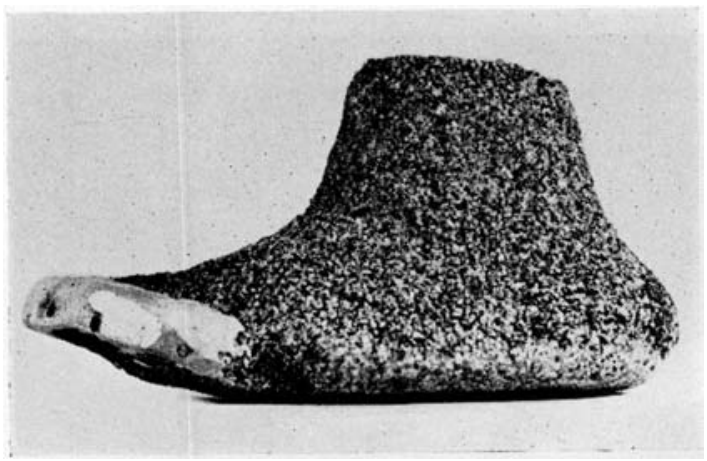

FIG. VI

The cork and polyester last, showing the toe spring or roll that has been formed by the sponge rubber padding and also the leather build-up over the toes in readiness for an open toe boot. The protruding heel can be seen.

\section{Io6 Leprosy Review}

only one layer of $6 \mathrm{~mm}$ thick leather needs to be tacked on to the front to eliminate the irregularities of the toes (Fig. VI).

As with other leprosy footwear where an insole is to be used inside the finished shoe the bottom of the last has to be built up to the required depth. The bottom of the last will of ten be uneven. This means that the insole is going to be of varying thicknesses and so the build-up must be the same. A sheet of $3 \mathrm{~mm}$. cork is glued on to the bottom of the last. The high parts are then rasped down until the last shows through. Another layer of cork is glued on and also rasped down. This is done until the bottom of the last is flat medial to lateral but not eliminating the toe spring. Once the sole is flat, thicker pieces of cork can be used for completing the build-up. The thickness of the build-up depends mainly on the shape of the foot but at least $10 \mathrm{~mm}$. should be left under the lowest part to allow room for a slight thickness of cork and latex moulding as well as the microcellular rubber inside the boot. The side of the cork build-up must be perpendicular when the last is in the upright position and not flare outwards or inwards; it should also blend into the sides of the last (Fig. VII).

If there is insufficient toe-spring in the last and the last has been adapted for a closed toe boot, the cork build-up under the leather packing can be rasped down to form a little toe-spring. This can be further increased by lightly glueing one or two layers of cork sheeting under the meta-

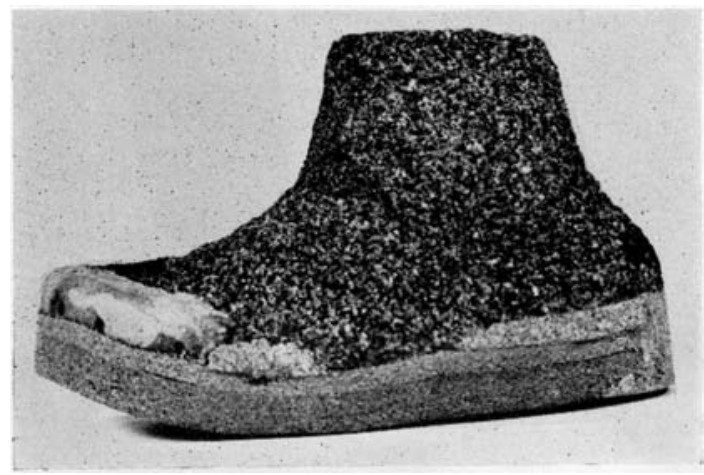

FIG. VII

The last with the cork build-up. This last is now ready for the shoe-maker. 
tarsal shaft area of the last, these are rasped down to blend into the cork build-up and to form a roll. When the boot is finished this piece of cork is removed and glued in place inside the boot.

The last is now ready for the shoe maker. If he is not experienced in the making of orthopaedic footwear he may find difficulty to cut the correct shaped paper pattern for the upper. This can be solved by sticking strips of adhcsive tape onto the last; these are then removed en masse and used as the model for cutting the paper pattern (Fig. VIII). A heel is usually not needed, but a low one should be used if the foot is going to be at all dorsiflexed when the patient stands.

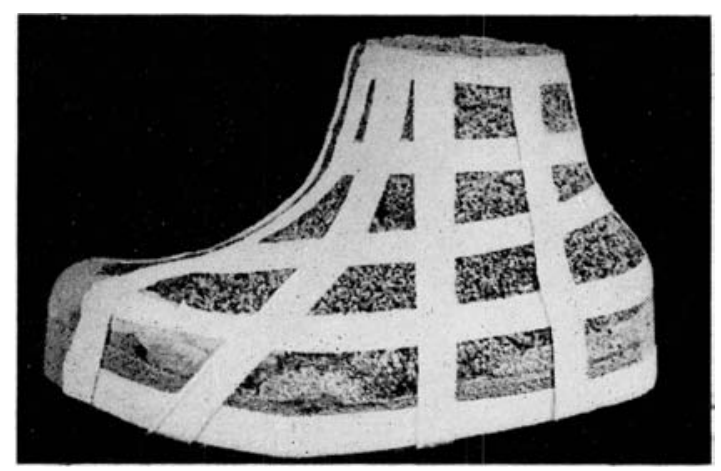

FIG. VIII

The last with strips of adhesive tape which will be removed en masse and used to cut the paper pattern.

At the finish the moulded cork and the latex insole is made in exactly the same way as already described. When an open toe boot is used, a strip of X-ray film is tucked into the front to prevent the cork from squeezing out (Fig. IX). At the finish it is removed and a strip of leather put in its place.

This work was supported by grants from the office of Vocational Rehabilitation, Department of Health, Education and Welfare of the United States Government.

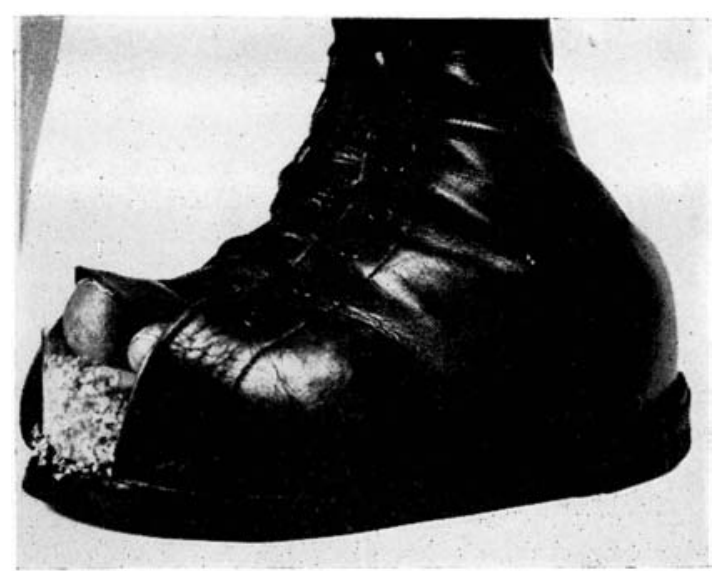

FIG. IX

The moulded cork insole being formed. The strip of X-ray film can be seen preventing the cork from squeezing out of the front.

We wish to acknowledge thanks to the Swiss Emmaus Association for the training stipend that was provided for $\mathrm{Mr} \mathrm{J}$. P. Girling while he was in Europe. We also thank the firm of Scott Bader \& Co. Ltd. for the technical advice and free materials that was given during the initial stages. Mr Sigamoney is thanked for the photographs.

\section{REF ERENCES}

I. BAUMANN J. H., GIRling J. P., BRAND P. W. (I963), Plantar Pressures and Trophic Ulceration, Journal of Bone and Joint Surgery, 45-B, $65^{2}$.

2. BRAND P. W., Personal Communication.

3. British Standard 3350 (I96I), Method of Measurement for Surgical Footwear.

4. Gleave J., Personal Communication.

5. HARRIS J., BRAND P. w., Patterns of Disintegration of the Tarsus in the Anaesthetic Foot, Journal of Bone and Joint Surgery, Accepted for Publication.

6. PRICE E. W. (1960), Studies of Planter Ulceration in Leprosy, VI: The Management of Plantar ulcers, Leprosy Review, 3 I : I 59 .

7. Polyester Handbook 1963, Scott Bader \& Co. Ltd., Printers Percy Lund, Humphries and Co. Ltd. London.

8. WARD D. J. (1962), Footwear in Leprosy, Leprosy Reriew $32: 94$. 